\title{
Analisis Pendekatan Historis Terhadap Diksi Istilah-Istilah Perekonomian dalam Al-Qur'an
}

\author{
Bustomi Bustomi \\ Institut Agama Islam Negeri Bengkulu \\ email: bustomihasan99@gmail.com
}

\begin{abstract}
Al-Qur'an is a holy book with very valuabel Arabic language. Its language style is a miracle that no human can imitate until the end of time. The content of the meaning is very broad and the lexical choices are super precise and thorough. The Qur'an came down in Mecca and Medina where the majority of the population work as traders. Hence, this article is aimed at analyzing historically the lexical choices used in the Al-Qur'an whose people are generally busy in commerce. This study uses a qualitative approach by adopting the content analysis method of Satori and Komariah (2010); an analysis focusing on the actual content in a script to determine certain words, themes, concepts, phrases, or sentences related to the objectives will be achieved. In this case, the object analyzed is certain vocabulary in the Qur'an which has economic nuances. The result of this study explains that the Qur'an uses many economic terms and vocabularies which are usually used by the Arab community as a merchant community. The use of economic vocabulary such as tijârah, mîzan, ajr, isytarâ and it's derivatives, and jazâ is not only used to regulate proper business procedures in worldly affairs, but is actually used to guide people to do good deeds in the hereafter interest.
\end{abstract}

Keywords: lexical choices; Arabic; economic words; the Qur'anic language style

\begin{abstract}
Abstrak
Al-Qur'an merupakan kitab suci berbahasa Arab yang sangat tinggi nilainya. Gaya bahasanya merupakan mukjizat yang tidak bisa ditiru oleh manusia mana pun sampai akhir zaman. Kandungan maknanya sangat luas dan pilihan katanya super jitu dan teliti. Al-Qur'an ini turun di Mekah dan Madinah yang penduduknya mayoritas berprofesi sebagai pedagang. Untuk itu, artikel ini bertujuan untuk menganalisis secara historis pilihan kata yang digunakan dalam Al-Qur'an yang masyarakatnya secara umum sibuk dalam perniagaan. Penelitian ini menggunakan pendekatan kualitatif dengan mengadopsi metode analisis isi ala Satori dan Komariah (2010), yakni analisis yang memfokuskan pada konten aktual dalam suatu naskah untuk menentukan kata-kata tertentu, temarema, konsep, frase, atau kalimat yang berhubungan dengan tujuan yang akan dicapai. Dalam hal ini, objek yang dianalisis adalah kosakata tertentu dalam Al-Qur'an yang bernuansa ekonomi. Hasil penelitian ini menjelaskan bahwa Al-Qur'an menggunakan banyak istilah dan kosakata ekonomi yang merupakan bahasa yang sering digunakan oleh masyarakat Arab sebagai masyarakat pedagang. Penggunaan kosakata ekonomi seperti tijârah, mîzan, ajr, isytarâ dan derivasinya, dan jazâ tidak hanya digunakan untuk mengatur tatacara berbisnis yang benar dalam urusan dunia, akan tetapi, dengan porsi yang lebih banyak, justru digunakan untuk menuntun agar melakukan amal saleh dalam urusan akhirat.
\end{abstract}

Kata kunci: diksi; bahasa Arab; istilah perekonomian; gaya bahasa Al-Qur'an

\section{Pendahuluan}

Al-Qur'an diturunkan kepada Nabi

Muhammad saw dengan bahasa Arab

Quraisy, yakni bahasa yang paling tinggi nilainya dibandingkan dengan bahasa suku-suku lain di Jazirah Arab. Karena begitu tingginya bahasa Arab Quraisy ini, mereka selalu memperlombakannya 
dalam bentuk syair, khutbah, petuah, atau nasihat. Syair-syair yang dinilai menang karena keindahan sastranya lalu digantung di Kabah sebagai penghormatan kepada penggubahnya sekaligus agar bisa dinikmati oleh yang melihatnya atau membacanya ${ }^{1}$. Penyair tersebut mendapat kedudukan yang istimewa karena telah mengangkat derajat dan reputasi kaumnya di mata dunia Arab ketika itu.

Banyak mufasir berpendapat bahwa yang dimaksud bahasa dalam ayat AlQur'an yang bunyi terjemahannya adalah "Sesungguhnya kami telah turunkan AlQur'an dengan bahasa Arab agar kalian berpikir" merupakan bahasa Arab yang mayoritas berdialek Quraisy², walaupun ada juga sarjana orientalis seperti Luxernberg yang menuduh bahwa alQur'an ini bukan asli dari bahasa Arab, tetapi berasal dari bahasa Syro-Aramik ${ }^{3}$. Menurut Wahid, sebelum Islam datang, di sekitar Mekah selalu diadakan kompetisi syair, petuah, nasihat, dan khutbah. Dalam kompetisi tahunan tersebut, dialek Arab Quraisy selalu diutamakan mengingat suku-suku Arab itu

${ }^{1}$ M. Quraish Shihab, Wawasan Al-Quran: Tafsir Tematik Atas Pelbagai Persoalan Umat (Mizan Pustaka, 1996), 115

2'Âli Abd al-Wâhid Al-Wâfî, Ilm Al-Lugah (Mesir: Martabat Nahdad Mishr bi al-Fujalah., 1962), 113.

${ }^{3}$ Muhammad Anshori, "Tren-Tren Wacana Studi Al-Qur'an dalam Pandangan Orientalis di Barat" 4, no. 1 (2018): 33. menggunakan dialeknya masing-masing. Mengingat bahasa Arab dialek Quraisy ini merupakan bahasa yang paling tinggi inilah, maka Al-Qur'an diturunkan dengan bahasa Arab Quraisy. Khalifah Usman bin Affan menetapkan dialek Quraisy sebagai satu-satunya dialek yang digunakan dalam menulis $\mathrm{Al}-\mathrm{Qur}$ 'an dan juga dialek yang digunakan untuk menulis hadis ${ }^{4}$.

Sebenarnya, banyak ulama yang berpendapat bahwa Al-Qur'an itu diturunkan dengan tujuh bahasa. Hal ini didasarkan pada hadis sahih Bukhari nomor 4705 yang menguraikan bahwa bahasa Al-Qur'an memuat beberapa bahasa kabilah Arab, yakni hadis yang berbunyi:

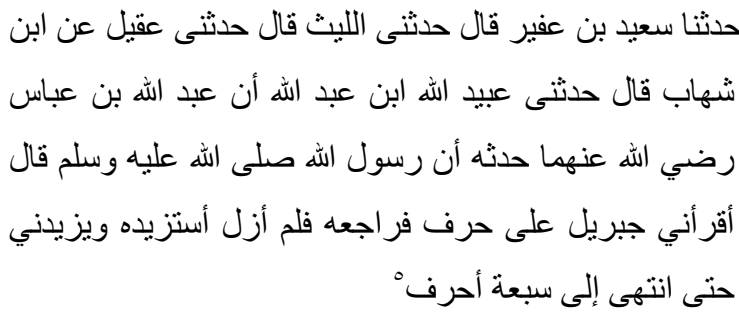

"Diceritakan kepada kami Said bin Ufair ia berkata, diceritakan kepada kami al-Lais ia berkata, diceritakan kepadaku Uqail dari Ibn Syihab ia berkata, diceritakan kepadaku Ubaidillah bin Abdullah bahwa Abdullah bin Abbas menceritakan kepadanya bahwa Rasulullah saw bersabda: Jibril telah membacakan padaku dengan satu huruf (dialek), maka aku pun kembali kepadanya

${ }^{4}$ Karim Hafid, "Relevansi Kaidah Bahasa Arab Dalam Memahami Al-Qur'an," 2016, 194.

${ }^{5} \mathrm{Abū}$ 'Abd Allāh Muhammad ibn Ismā'îl ibn Ibrāhīm ibn al-Mughīrah ibn Bardizbah al-Bukhari, Șahîh Al-Bukhari, 3 (Jakarta: Almahira, 2012), 1177. 
untuk meminta ditambahkan hingga berakhirlah pada sab'ah ahruf (tujuh dialek)".

Kata sab'ah ahruf mengandung banyak interpretasi di kalangan ulama sejak dulu. As- Suyuṭi dalam karyanya alItqân fì 'Ulûm al-Qur'ân mencatat bahwa yang dimaksud dengan sab'ah ahruf adalah beberapa bahasa kabilah Arab yang terbilang paling fasih, sedangkan kata $s a b^{\prime} a h$ hanya sebagai tanda isyarat banyak ${ }^{6}$. Sementara itu, Manna al-Qatțân berbeda pendapat dengan As-Suyuti. Menurut al-Qațân, yang dimaksud sab'ah ahruf adalah satu kata yang bisa dibaca tujuh versi. Beberapa ulama hadis dan tafsir pun kemudian tidak dalam satu kesepakatan dalam memahami sab'ah ahruf ini.

Di Jazirah Arab terdapat beberapa kabilah, diantaranya yaitu kabilah Huzail, Tamim, Yaman, kabilah Thayyi', Uzdu, Rabi'ah, Hawazin, dan Sa'ad bin Bakrin. Dari sejumlah kabilah tersebut, yang paling fasih dalam melafalkan bahasa Arab, khususnya Al-Qur'an, adalah kabilah Qurays, yakni kabilah dari keluarga Nabi Muhammad saw. Hal tersebut berdampak pada Al-Qur'an lebih banyak menggunakan bahasa kabilah Qurays daripada bahasa-bahasa kabilah

${ }^{6}$ Jalaluddin As-Suyûți, Al-Itqân Fi Ulûm al-Qu'rân (Bairut: Dar al-Fikr, 1996), 76.

7Mannâ Khaîl al-Qațân, Mabâhis Fî̀ Ulûm AlQur'ân (Riyad: Mansyurât al-'Aṣr al-Hadîs, 1973), 153. yang lain. Hal ini sesuai dengan pendapat Usman bin Affan yang diriwayatkan oleh al-Bukhari (nomor: 4987) sebagaimana dikutip oleh Ibn al-Qayyim al-Jauziyyah sebagai berikut ${ }^{8}$ :

$$
\begin{aligned}
& \text { إذا اختلفتم أنتم وزيد بن ثابت في شئ من القرآن فاكتبوه بلسان } \\
& \text { قريش؛ فإنه أكثر ما نزل بلسانهم }
\end{aligned}
$$

"Jika kalian berbeda pendapat dengan Zaid bin Sabit dalam teks Al-Qur'an maka tulislah dengan bahasa Quraisy karena mayoritas AlQur'an turun dengan dialek Quraisy".

Berdasarkan fenomena sejarah tersebut, muncullah dugaan kuat bahwa Al-Qur'an banyak menggunakan bahasa ekonomi dalam mengatur dan menuntun umat manusia menuju jalan yang diridoi Allah swt. Penggunaan pilihan kata bahasa ekonomi dalam Al-Qur'an sangat menarik untuk dikaji dan dianalisis.

\section{Hasil dan Pembahasan}

\section{Keterkaitan Antara Suku Quraisy dengan Diksi Bahasa Ekonomi}

Mengapa dialek bahasa Quraisy mengungguli dialek-dialek lainnya di Arab? Al-Wâfî̀ ${ }^{9}$ dan Halâl ${ }^{10}$ menjelaskan bahwa faktor agama, ekonomi, politik, dan kekayaan bahasa merupakan faktorfaktor yang paling dominan yang

\footnotetext{
${ }^{8}$ Ibn Al Qayyim Al-Jauziyyah, I'lâm Al Muwaqqi'în 'an Rabb al-Âlamîn, 5 (Bairut: Dar al Fikr, 1977), 65.

9 'Âli Abd al-Wâhid Al-Wâfî, Figh Al-Lugah (Cairo: Dâr al- Nahdah Misr, 1945), 108.

10 Abd al-Gaffâr Hamîd Halâl, 'Ilm al-Lugah Baina al-Qadîm Wa al-Hadîs (Masir: Dar al-Qalam, 1986), 167-70.
} 
menyebabkan dialek suku Quraisy mengungguli dialek bahasa lainnya di Jazirah Arab. Faktor agama sangat memengaruhi bahasa Arab dialek Quraisy sebagai bahasa yang berkualitas unggul. Hal ini karena Quraisy memiliki akar historis dalam masalah keagamaan. Sebelum Islam, suku Quraisy telah memegang posisi kegamaan yang sangat penting. Mereka adalah tetangga Baitullah yang dipandang suci oleh orang-orang jahiliyyah Arab. Bagaimana pun juga, masyarakat Arab dari berbagai pelosok berdatangan ke Baitullah untuk berhaji; bertawaf lalu mengunjungi berhalaberhala mereka yang disimpan di Kabah dan mempersembahkan kurban untuk berhala yang disembah itu. Quraish Shihab dalam Tafsir Al-Misbah mengatakan bahwa masyarakat Quraisy dikagumi dan disegani oleh suku lainnya karena keteguhannya dalam memegang otoritas keagamaan. Mereka dikagumi dan ditakuti oleh masyarakat sekitarnya karena semua pihak mengagungkan Kabah, sementara suku Quraisy merupakan suku yang bertanggung jawab memelihara Kabah. Salain untuk memenuhi kebutuhannya, suku Quraisy juga memenuhi kebutuhan pokok para peziarahnya. Karena itu, mereka memperoleh rasa aman, baik dalam tempat pemukiman di sekitar Mekah maupun dalam perjalanan mereka ke luar kota. Penghormatan dan rasa kagum itu bertambah sejak dibinasakan pasukan gajah oleh Allah swt-yang sengaja datang untuk merobohkan Kabah sebagaimana diabadikan dalam Al-Qur'an surat al-fil.

Selain faktor agama, faktor ekonomi juga sangat berperan penting terhadap keunggulan dialek suku Quraisy ${ }^{11}$. Suku ini menguasai ekonomi karena mereka adalah elemen bangsa Arab yang paling pintar dan rajin. Mereka menguasai sebagian besar omzet perdagangan Jazirah Arab. Mereka adalah pedagang ulung dan pebisnis handal. Dengan membawa barang dagangan, mereka berpindahpindah dari satu daerah Jazirah Arab ke daerah Jazirah Arab lainnya, yakni dari utara (Syam) sampai ke selatan (Yaman) sebagaimana dikisahkan dalam Al-Qur'an surat al-Quraisy. Dalam hal ini, $M$. Quraish Shihab menjelaskan bahwa surat al-Quraisy ini menjelaskan adanya hubungan signifikan antara keistimewaan suku Quraisy yang pandai berbisnis dengan Mekah ${ }^{12}$. Pakar tafsir lulusan AlAzhar dengan predikat suma cumlude ini mengatakan bahwa disebutkannya frase "Pemilik rumah ini (haza al-bait: Kabah)"

11 Dr Parviz Kambin, A History of the Iranian Plateau: Rise and Fall of an Empire (iUniverse, 2011), 20. 12 Shihab, Wawasan Al-Quran, 537. 
dalam surat itu sengaja dipilih untuk mengingatkan mereka bahwa kehormatan yang mereka peroleh di tengah masyarakat sekitar serta rasa aman dan jaminan perjalanan berbisnis itu disebabkan karena mereka adalah penduduk kota tempat rumah Allah itu ada. Seandainya Allah tidak menempatkan rumah-Nya di sana, niscaya mereka tidak akan memperoleh aneka keistimewaan dan kemudahan itu.

Selain letak daerahnya yang strategis, suku Quraisy menguasai pengaruh keagamaan dan perekonomian yang secara langsung memiliki pengaruh politik terhadap daerah-daerah Arab lainnya pada masa Jahiliah ${ }^{13}$. Karena itu, tidak bisa dibantah lagi ketika dialek mereka mengalahkan dialek-dialek lainnya. Karena itu, terdapat hubungan yang kuat antara bahasa Al-Qur'an dengan bahasa Arab Quraisy.

Apa hubugannya antara suku Quraisy, bahasa Arab, dan bahasa ekonomi dalam Al-Qur'an? Sedikitnya, untuk menjawab pertanyaan ini terdapat petunjuk dari uraian di atas. Jika pun uraian di atas belum cukup menjadi petunjuk adanya keterikatan antara tiga istilah itu, maka berikut ini penjelasaan

13 Suaidi Suaidi, "DIALEK-DIALEK BAHASA ARAB," Adabiyyāt: Jurnal Bahasa dan Sastra 7, no. 1 (July 31, 2008): 79, https://doi.org/10.14421/ajbs.2008.07105. keterikatan antar ketiganya. Penamaan Quraisy berasal dari nama lain dari Fihryang merupakan leluhur Nabi Muhammad saw. Nama Fihir atau Quraisy inilah yang kemudian menurunkan sampai Qushay bin Kilab. Silsilah lengkapnya adalah Muhammad bin Abdullah bin 'Abd alMuṭalib bin Hâsyim bin 'Abd alManâf bin Qushay bin Kilab bin Murra bin Kaa'b bin Lu'ay bin Ghalib bin Quraisy (Fihr) bin Malik bin Nazar bin Kinanah bin Khuzaymah bin Mudrikah bin Ilyas bin Mazar bin Nazar bin Ma'ad bin Adnan bin Ismail bin Ibrahim.

Mengapa Fihr lazim disebut Quraisy yang kemudian membentuk suatu kabilah yang disebut Kabilah Quraisy? Jawabannya adalah karena Fihr adalah sosok yang menguasai perdagangan diantara kabilah-kabilah yang lain. Fihr adalah pebisnis ulung yang merajai perdagangan dunia Arab.

Ibn Manzur dalam Lisân al-Arâb menjelaskan bahwa kata Quraisy diambil dari kata "qursy" yang artinya uang atau nilai tukar mata uang yang diindonesiakan menjadi kurs (rate of exchange). Kata "qursy" ini kemudian searti dengan "kurs" yang dalam KBBI artinya adalah "nilai mata uang suatu negara yang dinyatakan dengan nilai mata 
uang negara lain". Uraian Ibn Manzur itu diungkapkan sebagai berikut ${ }^{14}$.

وقيل سميت بذلك لتقرشها أي تجمعها إلى مكة من حو اليها بعد تفرقها في البلاد حين غلب عليها قصي بن كلاب وبه سمي قصي مجمعا وقيل سميت بقريش بن مخلا بن غالب بن فهر كان صاحب عيرهم فكانوا يقولون قدمت عير قريش بن بن بن وخرجت عير قريش وقيل سميت بذلك لتجرها وتكسبها وضربها في البلاد تبتغي الرزق وقنيل سميت وبل بذلكيت لأنهر

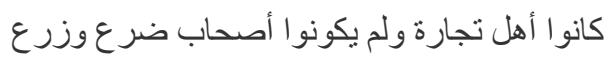

"Dikatakan bahawa disebut demikian (Quraisy) itu karena suku itu 'mengumpulkan' (barang dagangan itu) ke Mekah setelah tersebar di negeri tersebut setelah dikalahkan oleh Qusay bin Kilâb. Karena itu, Qusay disebut orang yang mengumpulkan. Dikatakan juga bahwa nama Quraish itu dihubungkan kepada Ibn Mukhalid bin Gâlib bin Fihr yang merupakan saudagar pemilik barang perniaagaan. Mereka mengatakan telah terjadi impor dan ekspor barang dagangan Quraish. Dinamakan demikian (Quraisy) adalah karena perniagaannya dan mata pencahariannya di negeri tersebut dalam mencari rezeki. Dan, dinamakan demikian (Quraisy) itu karena mereka merupakan ahli berdagang, bukan ahli berternak dan bercocok tanam"

Memperhatikan beberapa kronologi sejarah suku Quraisy dan ditambah lagi dengan pendapat Ibn Manzur dalam kamus Lisân al-'Arab di atas, agaknya sukar dibantah jika nama Quraisy itu muncul karena kiprah suku Arab Quraisy tersebut dalam menguasai perdagangan dunia Arab. Hal ini pun kemudian

14 Ibn Manzur, "Lisân Al-'Arab," n.d. http:/ / www.lesanarab.com/kalima/\%D9\%82\%D8\%B1\% D8\%B4. diperkuat dengan kandungan surat alQuraisy (106) ayat 1-6 yang secara khusus menggambarkan kebiasaan berdagang suku Quraisy, yakni kebiasaan melakukan perdagangan pada musim dingin dan musim panas. Secara tidak langsung, ayat tersebut menginformasikan bahwa mereka telah mengenal kebiasaan ekspor (mendatangkan barang) dan impor (mengirimkan barang). Mereka telah melakukan kegiatan hubungan dagang internasional. Pada musim dingin (asysyitâ’) mereka pergi ke wilayah Yaman. Di tempat ini, mereka mengambil barang dagangan berupa kain sutera, barang pecah belah, rempah-rempah, bahan kapur barus, dan lainnya untuk kemudian dikirim ke Syam (Suriah sekarang). Sedangkan pada saat musim panas (așșa iff), mereka kemudian mengekspornya. Demikian sebaliknya, mereka mengambil barang dagangan berupa gandum untuk bahan membuat roti dan buah-buahan dari Syam kemudian dibawa ke Yaman untuk dijual.

Kemahiran suku Quraish dalam berbisnis mengakibatkan suku ini unggul, cerdas, dan berwibawa. Dalam urusan politik pun, suku Quraisy adalah suku yang paling layak memimpin. Disebutkan dalam riwayat Anas r.a, Nabi Muhammad saw bersabda yang intinya bahwa para imam itu dari Quraisy. Jika memerintah, 
mereka adil, jika berjanji maka akan ditepati, jika diminta belas kasihan maka mereka akan mudah melakukannya. Itu semua akibat dari kompetensi yang dimiliki oleh suku Quraish dan ditambah lagi keimanan mereka yang sangat kuat kepada Allah swt.

Namun demikian, sebelum fathu Mekah, suku Quraisy adalah suku yang kali pertama menolak risalah kenabian Muhammad saw. Oposan terhadap Muhammad saw adalah suku dari keluarganya sendiri (orang dalam). Penolakan itu dilakukan secara masif, ekspresif, dan terbuka kepada Nabi Muhammad saw. Dalam keadaan itulah, Al-Qur'an diturunkan sebagai petunjuk bagi umat manusia, yakni secara khusus, historis, dan geografis memberikan bimbingan kepada pengikut nabi yang ada di Mekah dan Madinah dan memberikan petunjuk bagaimana agar berada di jalan yang benar.

\section{Kesempurnaan Pilihan Kata Bahasa Al-} Qur'an

Pilihan kata yang tepat yang diucapkan oleh seseorang dalam berkomunikasi akan menunjukan bahwa bahasa yang digunakannya itu berkualitas karena pengguna bahasa akan selalu memlih suatu kata agar terlihat tepat, cermat, dan sesuai ${ }^{15}$. Penelitian Yuliawati menyimpulkan bahwa penggunaan pilihan kata dipengaruhi oleh konteks sosial dan budaya ${ }^{16}$.

Keraf ${ }^{17}$ mengemukakan tiga kesimpulan utama mengenai diksi. Yang pertama pemilihan kata atau diksi itu mencakup pengertian kata-kata mana yang akan dipakai untuk menyampaikan suatu gagasan, bagaimana membentuk pengelompokan kata-kata yang tepat atau menggunakan ungkapan-ungkapan yang tepat, dan gaya mana yang paling baik digunakan dalam situasi. Kedua, pilihan kata atau diksi adalah kemampuan membedakan secara tepat nuansa-nuansa makna dari gagasan yang ingin disampaikan, dan kemampuan untuk menemukan bentuk yang sesuai (cocok) dengan situasi dan nilai rasa yang dimiliki kelompok masyarakat pendengar. Ketiga, pilihan kata yang tepat dan sesuai hanya dimungkinkan oleh penguasaan sejumlah besar kosa kata atau perbendaharaan kata bahasa itu. Sedangkan yang dimaksud perbendaharaan kata atau kosa kata suatu

${ }^{15}$ Roza Permata Sari and Novia Juita, “Analisis Penggunaan (Diksi) Pilihan Kata Oleh Pejabat Legislatif dan Tokoh Partai Tingkat Provinsi Dalam Media Sosial Facebook," Jurnal Bahasa dan Sastra 6, no. 4 (June 25, 2019): 590, https:// doi.org/10.24036/81046050.

${ }^{16}$ Susi Yuliawati, "Pilihan Kata Dan Konstruksi Perempuan Sunda Dalam Majalah Manglè Kajian Linguistik Korpus Diakronik," Paradigma, Jurnal Kajian Budaya 7, no. 2 (January 24, 2018): 138, https://doi.org/10.17510/paradigma.v7i2.172.

${ }^{17}$ Dr Gorys Keraf, Diksi dan Gaya Bahasa (Gramedia Pustaka Utama, 2009), 24. 
bahasa adalah keseluruhan kata yang dimiliki oleh sebuah bahasa.

Berbicara mengenai bahasa AlQur'an, Shihab mengatakan bahwa tiada satu kata bacaan pun seperti Al-Qur'an yang dipelajari redaksinya, bukan hanya dari segi penempatan kata demi kata, seperti pilihan kata, melainkan juga arti kandungannya yang tersurat, tersirat, bahkan sampai pada kesan-kesan yang ditimbulkan oleh jiwa pembacanya, dan kemudian dituliskan ratusan ribu jilid tafsirnya generasi demi generasi hingga kini ${ }^{18}$. Tiada satu bacaan pun seperti AlQur'an yang dipelajari, dibaca, dipelihara bermacam-macam riwayat cara membacanya, dan disampaikan oleh sekian banyak orang yang tidak mungkin berbohong.

Kalam Allah swt yang berupa AlQur'an ini memuat kosakata yang super sempurna yang tidak bisa ditandingi oleh pakar bahasa mana pun sejak wahyu itu diturunkan hingga hari kiamat ${ }^{19}$. Ketepatan pilihan katanya tidak ada satu pun yang meleset dan tersusun sangat rapi. Jika al-Qur'an itu ibarat bangunan, kosakata itu ibarat susunan-susunan material yang tertata super rapi, tepat, dan

${ }^{18}$ M. Quraish Shihab, Mukjizat Al-Quran: Ditinjau Dari Aspek Kebahasaan, Aspek Ilmiah, Dan Pemberitaan Gaib (Mizan Pustaka, 1997), 60.

19Syahrul Rahman, "Pro Kontra I'jaz Adady Dalam Al-Qur'an," Jurnal Ushuluddin 25, no. 1 (June 21, 2017): 37, https://doi.org/10.24014/jush.v25i1.2175. jitu; jika ada satu saja material yang salah tempat, maka akan rapuhlah bangunan itu.

Sedikit pun tidak ada penggunaan kata yang meleset, keliru, apalagi salah. Sebagai contoh, Shihab menyebutkan bahwa Allah swt sengaja memilih kata murḍi'un (مرضعة) untuk ibu menyusui di surat al-hajj ayat ${ }^{20}$. Dalam bahasa Arab, Shihab menjelaskan bahwa kosakata yang tepat untuk wanita hami adalah إمراة حامل, wanita wanita yang sedang haid adalah dan wanita menyusui adalah مرضع، Penggunaan kata sifat إمراة مرضع untuk wanita (muaanas) sebenarnya menyalahi kaidah yang umum karena kata benda untuk muanas secara umum seharusnya menggunakan ta marbûțah (ö). Akan tetapi, penggunaan kata untuk wanita justru keliru karena orang yang bisa hamil, haid, dan menyusui hanyalah wanita. Lalu, mengapa dalam al-Qur'an surat al-Hajj ayat 2 Allah memilih kata مرضعة ? Menurut Shihab, justru Allah maha teliti atas segala kekeliruan dan kosakata yang digunakan itu merupakan pilihan kata yang jitu. Penggunaan kata مرضعة menunjukan bahwa pada hari kiamat nanti perempuan yang sedang menyusui dan sedang hamil itu lupa diri karena

\footnotetext{
${ }^{20}$ Shihab, Mukjizat Al-Quran, 103-4.
} 
adanya kejadian yang sangat dahsyatnya yang akan membinasakan semua makhluk hidup. Karena itu, wanita yang sedang menyusui itu berlarian dengan sangat kencangnya sampai lupa diri bahwa dirinya itu sedang menyusui atau sedang hamil.

Dikaji dari berbagai disiplin ilmu apa pun, ternyata al-Qur'an menggunakan gaya bahasa dan gramatika yang sangat khas, yakni pilihan kata yang tepat, makna yang utuh, dan kalimat yang sempurna ${ }^{21}$. Al-Jurjani mengatakan bahwa gaya bahasa al-Qur'an merupakan mukjizat tersendiri yang berbeda dengan gaya bahasa orang-orang Arab'22. Menurutnya, kekhasan gaya bahasa alQur'an itu adalah karena ia memiliki (1) nazam, yakni keterikatan antarunsur dalam kalimat ${ }^{23}$, (2) setiap kata yang tersusun dalam nazam itu mengikuti makna, yakni suatu kalimat dapat tersusun karena maknanya sudah tersusun terlebih dahulu, (3) peletakan kata itu sesuai dengan kaidah gramatika bahasa Arab sehingga berfungsi secara utuh dan kuat, (4) huruf-hurufnya memiliki kekhasan tersendiri sehingga

\footnotetext{
21Syihabuddin Qalyubi, Stilistika Al-Qur'an: Makna Di Balik Kisah Ibrahim (LKIS Pelangi Aksara, 2008), 4.

22 Abd al-Qâhir Al-Jurjani, Kitâb Dalâil Al-I'jâz (Kairo: Maktabah al-Khanzi, 2004), 55-56.

${ }^{23}$ Amidu Olalekan Sanni, "Hussein Abdul-Raof. Arabic Rhetoric. A Pragmatic Analysis. Reviewed by Amidu Olalekan Sanni," Middle Eastern Literatures 15, no. 1 (April 1, 2012): 97-98, https:// doi.org/10.1080/1475262X.2012.657397.
}

menyatu dengan makna yang tepat dan komprehensif, dan (5) semua huruf, kata, dan frase dalam kalimat berfungsi sesuai dengan porsinya masing-masing dan yang semestinya.

\section{Contoh Pilihan Kata Bahasa Ekonomi dalam Al-Qur'an}

Kisah bahwa empat suku Quraisy dari keluarga Abd al-Manaf, yakni Hasyim, al-Muthalib, Abd as-Syams, dan Naufal, merupakan anugerah ilahi memperoleh jaminan keamanan dari penguasa Bizantium, Persia, Abisinia, dan Himyari24. Tercatat bahwa Hasyim memperoleh jaminan keamanan dari kekaisaran Bizantium; Al-Muthalib memperoleh jaminan yang sama dari penguasa Yaman; Abdusy Syams mendapatkannya dari penguasa Abisinia, dan Naufal memperolehnya dari kekaisaran Persia. Jaminan keamanan sejenis juga diperoleh dari suku-suku Arab di sepanjang perjalanan keempat bersaudara anggota suku Quraisy itu.

Dari latar historis ini, apa yang disimpulkan oleh Yuliawati ${ }^{25}$ bahwa pilihan kata itu dipengaruhi oleh faktor historis yang mencakup sosial dan budaya

24 Sharifah Nazneen Agha, "The Ethics of Asylum in Early Muslim Society," Refugee Survey Quarterly 27, no. 2 (January 1, 2008): 30-40, https://doi.org/10.1093/rsq/hdn031.

${ }^{25}$ yuliawati, "Pilihan Kata dan Konstruksi Perempuan Sunda dalam Majalah Manglè Kajian Linguistik Korpus Diakronik." 
nampaknya sulit untuk dibantah. Hal senada juga diungkapkan oleh Saputri dkk bahwa pilihan kata itu harus sesuai dengan situasi dan tempat penggunaan kata itu diucapkan ${ }^{26}$. Selain itu, pilihan kata tidak hanya memiliki ketepatan kata, tetapi harus memiliki makna yang dapat diterima berdasarkan situasi dan norma masyarakat ${ }^{27}$.

Kosakata dalam al-Qur'an bukanlah suatu kebetulan. Akan tetapi, kosakata yang membentuk bangunan ayat, surat, dan kitab suci Al-Qur'an ini merupakan pilihan kata yang tinggi maknanya dan sastranya. Pilihan kata yang bernuansa ekonomi dalam lembaran ayat-ayat Alqur'an tentu saja kosakata yang sengaja dipilih oleh Allah swt dengan rapi dan jitu. Wujud pilihan kata bahasa Al-Qur'an yang bernuansa ekonomi diklasifikasi berdasarkan tema-tema tertentu yang jumlahnya sangat banyak. Tidak ada kesepakatan mengenai jumlah ayat AlQur'an yang membicarakan masalah ekonomi. Hal ini karena penggunaan istilah ekonomi itu digunakan oleh alQur'an tidak hanya untuk membicarakan urusan dunia, tetapi juga untuk urusan

${ }^{26}$ Amelia Saputri, Mulyanto Widodo, and Sumarti Sumarti, "Diksi Dalam Poster Berbasis Elektronik Di Youtube Serta Implikasinya," Jurnal Kata (Bahasa, Sastra, Dan Pembelajarannya) 5, no. 1, Apr (2017): 2.

${ }^{27}$ Chori Latifah, Muhammad Rohmadi, and Edy Suryanto, "Penggunaan Diksi dalam Karangan Berita Siswa Sekolah Menengah Pertama" 4 (2016): 86. akhirat ${ }^{28}$. Akan tetapi, jika yang dibicarakan adalah hukum ekonomi, Abdul Wahab Khalaf menguraikan bahwa ayat-ayat Al-Qur'an yang membicarakan hukum ekonimi ada 10 ayat ${ }^{29}$.

Banyak para peneliti di bidang AlQur'an mengklasifikasi tema-tema ekonomi. Mahfudz ${ }^{30}$ misalnya, mengklasifikasi tema ekonomi berdasarkan (1) karakteristik ekonomi Islam yang mengandung prinsip ilahiyah [QS. Al-An`am: 162], prinsip keadilan dan ihsan [an-Nahl: 90], prinsip kebebasan [arRa`du: 11], dan prinsip tanggung jawab [al-An`am: 164]; (2) konsep kebutuhan, QS. Al-Qașaṣ: 77, Al-Isra': 29, dan AlFurqân: 67; (3) konsep kepemilikan, Q.S. Al-Baqarah: 284 dan az-Zariyyât: 19; (4) konsep produksi, Q.S. al-Baqarah: 30, alJâsiyah: 13, 'Ali ‘Imran: 131, al-Fûṣilât: 31, al-Fâtị: 1, dan al-Mulk: 15; (5) konsep distribusi, Q.S. al-Hasyr: 7, al-'An'am: 65, al-Fâtịi: 2, Hud: 116, al-Isra: 16, az-Zâriyât: 19, dan al-Baqarah: 219; (6) konsep konsumsi, Q.S. Tâhâ: 81, al-'An'am: 141, an-Nisâ: 29, al-Isrâ: 27, dan al-A'râf: 31; (7) prinsip perdagangan, Q.S. al-Baqarah: 283; (8) teori harga, Q.S. an-Nisâ: 29; (8) konsep

28 Taufik Adnan Amal, Rekonstruksi Sejarah AlQuran (Pustaka Alvabet, 2013), 7.

${ }^{29}$ Azhari Akmal Tarigan, Tafsir Ayat-Ayat Ekonomi Al-Qur'an: Sebuah Eksplorasi Melalui Kata-Kata Kunci (Cita Pustaka Media, 2012), 2.

30 Mahfudz, "Ayat-Ayat Dalam Ekonomi Islam (Versi Lengkap)," Blog Aang (blog), 2019, http:/ / mahfudzirfan.blogspot.com/2019/03/ayat-dalamekonomi-islam-versi-lengkap.html. 
uang, Q.S. Yusuf: 20, al-Kahfi: 19 dan alBaqarah: 279; (9) lembaga keuangan syariah, Q.S. an-Nisâ: 58, al-Muzammil: 20, al-baqarah: 275, 282, 27; 245; (10) kebijakan fiskal, Q.S. at-Taubah: 60, alAnfâl: 41, al-Hasyr: 7; dan (11) kebijakan moneter, Q.S. al-Baqarah: 275. Senada dengan itu, Majid juga mengklasifikasi prinsip-prinsip ekonomi dalam Al-Qur'an menjadi empat hal, yaitu (1) harta hakiki, (2) hukum bolehnya mencari harta, (3) kewajiban mentasarufkan harta secara hak, dan (4) prinsip keseimbangan, kesederhanaan, dan kedermawanan dalam ekonomi Islam ${ }^{31}$.

Dalam penelitian ini tidak diungkapkan ayat-ayat apa saja yang berhubungan atau yang menguraikan tentang ekonomi secara keseluruhan. Akan tetapi, dalam kajian ini, yang dipaparkan hanyalah contoh-contoh pilihan kata bahasa ekonomi dalam alQur'an yang dapat diuraikan sebagai berikut.

\section{Tijârah}

Dalam Al-Qur'an, perniagaan diungkapkan dengan kata tijârah dengan derivasinya (kata turunannya). Kata ini menjadi tema sentral dalam kehidupan masyarakat Arab ketika itu. Mnurut

31 Zamakhsyari Abdul Majid, "Ekonomi dalam Perspektif Alquran," AHKAM : Jurnal Ilmu Syariah 16, no. 2 (December 11, 2016): 251-60, https://doi.org/10.15408/ajis.v16i2.4455.
Taufik Adnan Amal, kata ini disebutkan dalam sembilan kesempatan dalam AlQur'an ${ }^{32}$. Selanjutnya, Amal juga menyebutkan bahwa penggunaan kata tijârah bukan hanya untuk perbisnisan, tetapi merupakan doktrin yang sangat mendasar sebagai orang yang beriman, yakni "perniagaan" mencari keuntungan pahala yang kelak menjadi bekal terselamatkannya dari siksa api neraka sebagaimana tercantum dalam QS. aş-Șaff ayat 10 sebagai berikut ini.

$$
\text { يايها الذين امنوا هل ادلكم على تجارة تتجيكم من عذاب اليم }
$$

"Hai orang-orang yang beriman, maukah kamu Aku tunjukan suatu perniagaan yang akan menyelamatkan kamu dari siksaan yang pedih"

Sebab turunnya ayat di atas adalah ketika para sahabat bertanya kepada Nabi Muhammad Saw tentang amalan yang paling disukai oleh Allah Swt dan setelah itu turunlah ayat ke-10 surat aş-Ṣaff tersebut ${ }^{33}$. Konsep perniagaan merupakan hal tidak asing lagi bagi masyarakat Mekah, terutama masyarakat Quraisy. Menurut Quraish Shihab, kata tijârah dalam surat aş-Ṣaff ayat 10 tersebut merupakan kata majazi dan maknanya adalah amal saleh ${ }^{34}$, hanya saja Allah Swt mengungkapkannya dengan istilah tijârah

\footnotetext{
32 Amal, Rekonstruksi Sejarah Al-Quran, 15.

33 Jalaluddin As-Suyûți, Lubâb An-Nuqûl Fî Asbâb an-Nuzûl (Cairo: Dâr al-Fikr, 2002), 570-71.

${ }^{34}$ M. Quraish Shihab, "Tafsir Al-Misbah," Jakarta: Lentera Hati, 14, 2 (2002): 31-32.
} 
agar mereka langsung memahami dan senang melakukanya sebagaimana mereka juga senang berdagang. Karena itu, setelah ayat 10 ini turun, para sahabat langsung bertanya perdagangan apa yang paling disukai oleh Allah dan setelah itu turunlah ayat yang ke-11 sebagai jawaban dari pertanyaan para sahabat tersebut bahwa perniagaan yang dimaksud adalah "Kamu beriman kepada Allah dan rasul-Nya, berjihad di jalan Allah dengan harta dan jiwamu. Itulah sebaik-baik kamu jika kamu mengetahui".

Kata tijârah dalam Al-Qur'an diungkapkan sebanyak sembilan kali dan diklasifikasi mejadi dua kategori, yaitu perdagangan kepada Allah dan perdaganagan dengan sesama manusia. Perdagangan kepada Allah ditujukan kepada manusia agar mereka beriman dan melakukan amal saleh, sedangkan perdagangan dengan sesama manuisa adalah agar mereka tidak memakan harta dengan cara batil (tidak melakukan muamalah secara batil), tetapi mereka disuruh melakukan tijârah atau perniagaan (an-Nisâ: 29), mereka boleh tidak mencatat jika praktik muamalah yang dilakukan adalah tijârah, tetapi jika transaksi jual-beli dilakukan dengan cara utang maka transaksinya itu harus dicatat dan disaksikan oleh dua orang (alBaqarah: 282).

\section{Isytarâ}

Penggunaan kata membeli isytarâ (bentuk lampau) atau yasytarî (bentuk muḍâri'= bentuk present) dalam Al-Qur'an hampir dimaksudkan dengan makna majazinya, bukan makna sebenarnya yaitu menjual barang dagangan atau benda berharga yang bersifat konkret. Dalam alBaqarah ayat 16 yang bunyi

$$
\text { كانو ا مهتدين الذين انتروا الضلالة بالهدى فما ربحت تجارتهم وما }
$$

"Mereka itulah orang yang membeli kesesatan dengan petunjuk. Maka, mereka tidaklah beruntung perniagaan mereka dan mereka bukanlah orangorang yang diberi petunjuk".

Penggunaan kata yasytarawî dalam ayat di atas merupakan pengungkapan perspektif negatif bagi orang-orang munafik. Perspektif negatif yang dimaksud adalah bahwa orang-orang munafik itu tidak mau mencari petunjuk, tetapi malah menukarnya dengan kesesatan. Dalam hal ini, Al-Qur'an menggunakan istilah yasytarû, membeli, yakni dengan teganya dan dengan niat jeleknya, orang munafik sengaja menukar atau membeli petunjuk (kebenaran) dengan kesesatan. Al-Qurtubi dalam tafsirnya mengatakan bahwa yang dimaksud yasytarawûu adalah orang munafik itu dengan sengaja membeli kekufuran dengan keimanan dan sengaja mengambil kesesatan dengan 
meninggalkan petunjuk ${ }^{35}$. Agar pesan seperti itu dimengerti secara jelas oleh orang Arab yang secara sosio-historis memiliki kebiasaan berdagang, penggunaan pilihan kata yasytaraw $\hat{u}$ sangat mengena dan mudah dimengerti.

Moeflich Hasbullah menyimpulkan bahwa dari sejumlah ayat Al-Qur'an yang menggunakan kata isytarâ atau yasytarû, yakni menukar ayat-ayat Al-Quran dengan harga murah, itu memiliki indikasi (1) menyediakan ayat untuk tujuan salah, (2) menjelaskan ayat secara samar, (3) menyampaikan kebenaran dengan tidak jelas, (4) enggan mempelajari ilmu-ilmu keislaman ${ }^{36}$. Zaroni menjelaskan bahwa kata isytarâ dan dengan bentuk derivasinya diungkapkan dalam Al-Qur'an sebanyak 25 kali dan mengandung makna transaksi antara manusia dengan Allah atau transaksi sesama manusia ${ }^{37}$. Dalam sejumlah ayat itu terdapat adanya motivasi transaksi yang mengharapkan pahala karena Allah dan motivasi untuk mendapatkan keuntungan pribadi

${ }^{35}$ Abu Abdillah Muhammad Ibn Al-Qurtubi, Tafsîr Al-Qurtubi/Al-Jâmi' Li Ahkâm al-Qur" An, vol. 4 (Beirut: Dar al-Kutub al-Ilmiyyah, 1967), 318-19.

36 Moeflich Hasbullah, "5 Indikasi Orang-orang yang 'Menjual Ayat dengan Harga Murah' | UIN SGD Bandung," August 28, 2013, https://uinsgd.ac.id/5indikasi-orang-orang-yang-menjual-ayat-dengan-hargamurah/.

37 Akhmad Nur Zaroni, "BISNIS DALAM PERSPEKTIF ISLAM," 2, IV (December 2007): 179. walaupun mengorbankan dan menukar ayat-ayat Allah.

Dipilihnya kata isytarâ beserta derivasnya itu karena orang Arab telah terbiasa menggunakannya dalam dunia bisnisnya. Namun demikian, walaupun yang digunakan adalah bahasa perdagangan yang telah terbiasa digunakan oleh orang Arab, kosakata itu ternyata fleksibel untuk semua zaman dan semua bangsa. Dalam istilah balagah, ArRâzi sebagaimana dikemukakan oleh Mubaidilah mengatakan bahwa isytarwî dalam Al-Baqarah: 16 itu merupakan gaya bahasa Al-Qur'an yang sangat tinggi dan dalam ayat itu digunakan majaz isti`arah ${ }^{38}$. Dalam ayat itu, kata isytarâ (membeli) dipinjam untuk mengganti kata mengganti (istabdala); kemudian dihubungkan dengan sesuatu yang sesuai, yakni keuntungan perdagangan (laba).

\section{Hisâb}

Kata hisãb dengan turunannya dalam Al-Qur'an diungkapkan sebanyak 59 kali $^{39}$. Amal mengungkapkan bahawa kata ini merupakan istilah yang lazim digunakan untuk menghitung untungrugi dalam dunia perniagaan ${ }^{40}$ atau istilah yang digunakan untuk menghitung

38 Mubaidillah Mubaidillah, “Memahami Isti'arah Dalam Al-Quran," Nur El-Islam 4, no. 2 (2017): 130-141.

39 Nurfadhillah Syam, Abd Haris Nasution, and Muhammad Chirzin, "Ma'Anil Quran: Haq, Hayat, Hubb, Hisab Dan Hidayah," August 1, 2018, https://doi.org/10.5281/ZENODO.1324990.

${ }^{40}$ Amal, Rekonstruksi Sejarah Al-Quran, 16. 
peredearan matahari (Q.S. al-'An`am: 96).

Dari makna penghitungan seperti itu, AlQur'an banyak menggunakannya untuk makna lain, yakni penghitungan amal kebaikan (Q.S. Ali Imran: 99, alMujâdalah: 9), kalkulasi amal selama hidup di dunia (al-Hâqah: 20 \& 26), hari penghitungan amal perbuatan (Ibrâhîm: $41)$.

Karena kata hisãb itu sudah sangat familier bagi orang Arab, penggunaan kata hisãb ini juga sangat tepat sasaran ketika digunakan untuk penghitungan amal kebaikan atau hari perhitungan. Karena amal perbuatan baik dan buruk manusia itu dicatat dalam kitab, hasil catatannya itu nanti akan dihitung; jika manusia amal kebaikannya banyak maka ia akan menerima kitab catatannya itu dari tangan kanan dan orang yang banyak catatan keburukannya maka ia akan menerimanya dari tangan kiri. Perhatikan penggunaan kata hisãb dalam ayat (alInsyiqâq: 7-11) sebagai berikut; yakni ketika istilah ekonomi digunakan untuk penghitungan amal perbuatan manusia.

فأما من اوني كتابه بيمينه ـ فسوف يحاسب حسابا يسيرا ـ و و ينقلب الى اهله مسرورا. و اما من اوتي كتابه وراء ظهره. فسوف يدعوا ثبورا ــ ويصلى سيرا.

"Adapun orang yang diberi kitab dari sisi kanannya, Maka, ia akan dihisab (diperiksa) dengan pemeriksaan yang mudah. Dan, ia akan kembali kepada keluarganya dengan gembira. Dan, adapun orang yang diberi (catatan) kitabnya itu dari belakang. Maka, ia akan berteriak celakalah aku. Dan, ia akan masuk ke neraka yang menyala-nyala".

Ragib al-Asfihâni menguraikan makna hisãb yang beragam ${ }^{41}$. Menurutnya, sesuai dengan konteksnya, kata hisãb ini akan berubah menjadi berbagai makna yang berbeda. Kata hisãb bisa bermakna (1) perhitungan [al-Hâqah: 20, 26, al'An'am: 96), (2) hitungan yang tak terhingga [an-Nabâ: 36, al-Baqarah: 212, Gâfir: 40], (3) cukup [al-Mujâdilah: 8, Ali 'Imrân: 173], (4) azab [at-țalâq: 8, Ali Imrân: 19], dan (5) sangkaan [al-Ankabût: 2-4].

\section{Mîzân, dan Kail}

Dalam dunia perdagangan tentu saja dikenal sebuah alat yang disebut timbangan atau takaran. Alat ini dipakai untuk mengukur barang dagangan berdasarkan berat dan ringan yang memiliki dua penampang sebelah kanan dan sebelah kiri yang beratnya sama jika tidak ditambahi beban berat di antara salah satunya. Kebiasaan jelek para pedagang biasanya membubuhi sesuatu di salah satu penampang takarannya sehingga ketika barang dagangannya itu ditimbang, ukuran beratnya akan berkurang.

Timbangan yang dalam bahasa Arab disebut mîzan atau wazan dan takaran

${ }^{41}$ Raghib Al-Isfahani, "Al-Mufradat Fi Gharib alQur'an," Qom: Darolkotob Publication, 1961, 232. 
disebut kail. Kedua kosakata ini banyak menghiasi ayat-ayat Al-Qur'an. Timbangan atau mîzan ini bersifat objektif karena ia akan mengukur berdasarkan berat sesuatu. Dengan keobjektifan inilah maka mîzan akan bersifat adil yang dalam Al-Qur'an disebut qist seperti surat asySyu`ara: 182 yang berbunyi: وزنوا بالقسطاس "timbanglah dengan timbangan yang 'adil' dan lurus". Dalam surat al-Isrâ: 35 kata kail dan wazan diungkapkan dalam satu rangkaian ayat: و اوفوا الكيل اذا كلتم وزنوا : بالقسطاس المستقيم ج ذللك خير واحسن تأويلا "Sempurnakanlah takaran apabila kamu menakar, dan timbanglah dengan neraca yang benar. Itulah yang lebih baik (bagimu) dan lebih baik (akibatnya)".

Kebiasaan para pedagang yang curang yang selalu mengurangi timbangan dikecam dalam sebuah surat Al-Qur'an yang khusus membicarakan orang-orang yang curang yang disebut dengan al-Mutaffifin. Dalam ayat 1-6 surat al-Mutaffifin ini Allah mengecam keras mereka yang berlaku curang dalam perdagangan, yakni mengurangi takaran dan timbangan. Amal mengatakan bahwa praktik kecurangan dalam berdagang, terutama dalam mengurangi timbangan itu begitu massif terjadi di masyarakat Mekah dan masyarakat Yahudi
Madinah $^{42}$. Untuk itulah, Al-Qur'an mengecam praktik curang mengurangi timbangan karena merugikan pembeli dan menghancurkan sendi-sendi keadilan.

Dari pengertian ekonomi, kata mîzan kemudian digunakan untuk timbangan amal kebaikan kelak di akhirat. Al-Qur'an mengemukakan bahwa kata hisãb itu biasanya didahulukan daripada kata mîzan. Ini karena amalan-amalan manusia dihitung (dihisab) dahulu lalu setelah itu ditimbang untuk menentukan balasan dari perbuatan manusia semasa hidup di dunia. Perhatikan surat Al-Mu'minûn: 102 intinya jika manusia itu berat timbangannya (amalnya), maka mereka

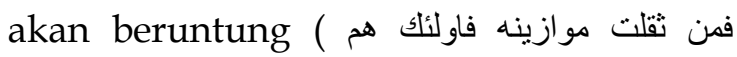
(الفملحون). Ayat berikutnya menyebutkan bahwa jika timbangannya ringan maka mereka akan rugi sendiri dan akan masuk neraka jahanam yang kekal di dalamnya ( ومن خفت موازينه فأولئك الذين خسروا (انفسهم فى جهنم خالدون Dalam hadis sahih Bukhari nomor 6406 disebutkan bahwa kata mîzan secara spesifik ditujukan untuk mengimbang amal kebaikan umat manusia. Dikatakan bahwa ada dua kalimat yang ringan diucapkan oleh lisan, tetapi berat di mîzan, dan lebih disukai oleh Zat Yang Maha Pengasih, yaitu subhânallâh al-'azim dan subhânallâh wa

${ }^{42}$ Amal, Rekonstruksi Sejarah Al-Quran, 16. 
bihamdih ${ }^{43}$. Kata mîzan dalam hadis ini secara eksplisit mengacu pada timbangan amal.

\section{Ajr dan Jazâ}

Kata ajr yang bermakna imbalan, upah, pahala, atau balasan digunakan dalam Al-Qur'an sebanyak 108 kali yang tersebar dalam 39 surat ${ }^{44}$ Secera seimbang, ajr digunakan sebanyak 54 kali dalam ayat-ayat makiyah dan 54 kali dalam ayat-ayat madaniyah. Kata ajr yang sudah tidak asing lagi bagi masyarakat Arab-yakni bermakna upah kerja dalam kegiatan ekonomi-secara umum digunkan untuk makna pahala atau balasan ganjaran di akhirat dalam AlQur'an. Namun demikian, ada juga kata ajr yang digunakan untuk balasan di dunia seperti pada Q.S. Al-Amkabût: 27; al-A'raf: 113; Yusuf: 57; dan an-Nahl: 41.

Dalam urusan dunia kerja, upah biasanya diberikan sesuai dengan kinerjanya. Besar kecilnya upah disesuaikan dengan hasil kerja seseorang walaupun ada juga misalnya bonus yang diberikan karena prestasi kerja karyawan. Akan tetapi, dalam urusan akhirat, AlQur'an menyebutkan bahwa balasan (ajr) yang diberikan kepada orang yang

${ }^{43}$ Imam al-Bukhari, Şaĥhh Al-Bukhari, vol. 8 (Masir: Dar at-Taufiq, 2012), 168.

44 Abdul Rahman Rusli Tanjung, "STUDI TERHADAP KATA-KATA YANG SEMAKNA DENGAN MUSIBAH DALAM ALQURAN," Analytica Islamica 2, no. 2 (2013): 270. melakukan amal saleh itu lebih baik (lebih banyak) dan boleh jadi berlipat. Hal ini bisa dilihat dalam surat an-Nahl: 97 yang berbunyi:

من عمل عملا صالحا من ذكر او انثى وهو مؤمن فلنحيينه حباة طيبة ولنجزينهم اجر هم بأحسن ما كانو ا يعملون

"Barang isap yang mengerjakan amal saleh baik laki-laki maupun perempuan dalam keadaan beriman, maka sesungguhnya akan kami berikan kepadanya kehidupan yang yang baik dan akan kami berikan balasan kepda mereka pahala yang lebih baik dari yang telah mereka lakukan".

Kata yang identik dengan ajr adalah kata jazâ. Kata ini pun artinya adalah ganjaran, imbalan, atau balasan. Dalam Al-Qur'an, kata jazâ diulang sebanyak 118 kali dan yang tersebar dalam 47 surat. Menurut Ibn Manzur, makna kata jazâ adalah balasan yang setimpal45. Artinya, seseorang yang melakukan perbuatan sesuatu akan diberi balasan sesuai dengan perbuatan itu sebagaimana disebutkan oleh surat al-Mu'minun: 111 yang berbunyi:انى جزيتهم اليوم بما صبروا أنهم هم الفائزون, "sesungguhnya kami memberi balasan kepada mereka pada hari ini karena kesabaran mereka; sesungguhnya mereka itulah orang-orang yang menang". 


\section{Kesimpulan}

Dua kota tempat Al-Qur'an diturunkan, yakni Mekah dan Madinah, merupakan pusat perbisnisan internasional ketika itu. Mekah merupakan pusat perniagaan yang sangat makmur dan Madinah juga merupakan oase kaya yang juga menjadi kota perdagangan walaupun tidak seramai Mekah. Dalam kajian sejarah, tidak bisa dibantahkan bahwa supremasi perniagaan penduduk Quraisy memiliki pondasi religius yang sangat kental. Ini semua bermuara pada posisi Kabah di kota Mekah. Konsekuensinya, Mekah menjadi pusat perdagangan bagi bangsa-bangsa Arab yang tentu saja sangat menguntungkan bagi aktivitas perbisnisan di kota kelahiran Nabi Muhammad saw itu.

Sebagai kota niaga, bahasa-bahasa perdagangan atau budaya komunikasi yang bernuansa ekonomi merupakan bahasa yang sangat familier bagi penduduknya. Dalam kondisi seperti inilah, Al-Qur'an turun kepada Nabi Muhammad saw. Karena itu, sangatlah tepat jika konsep-konsp dan istilah-istilah perekonomian seperti tijârah, isytarâ \& derivasinya, mîzan, ajr, jazâ, dan qard menjadi pilihan kata yang digunakan dalam Al-Qur'an. Para pakar bahasa pun meyakini bahwa istilah-istilah perekonomian merupakan kosakata yang fleksibel berlaku bagi semua orang dan bagi setiap zaman karena setiap orang di dunia ini akan bersentuhan dengan apa yang disebut perdagangan.

Keistimewaan bahasa Al-Qur'an adalah tidak hanya bahasa yang bernilai tinggi yang tidak bisa ditandingi oleh siapa pun sampai akhir zaman, tetapi merupakan informasi sejarah, berita isyarat gaib, tuntunan untuk beramal saleh, aturan hukum-hukum sayara, dan petunjuk bagi orang-rang yang beriman. Untuk itu, penggunaan istilah-istilah perekonomian yang menghiasai ayat-ayat Al-Qur'an itu lebih banyak diarahkan ke urusan akhirat di samping untuk tuntutan teknis tatacara berbisnis yang benar, penuh berkah, dan maslahat bagi orang banyak.

\section{Referensi}

1. Agha, Sharifah Nazneen. "The Ethics of Asylum in Early Muslim Society." Refugee Survey Quarterly 27, no. 2 (January 1, 2008): $\quad 30-40$. https://doi.org/10.1093/rsq/hdn0 31.

2. Al-Isfahani, Raghib. "Al-Mufradat Fi Gharib al-Qur'an." Qom: Darolkotob Publication, 1961, 297.

3. Al-Jauziyyah, Ibn Al Qayyim. I'lâm Al Muwaqqi'în 'an Rabb alÂlamîn. 5. Bairut: Dar al Fikr, 1977.

4. Al-Jurjani, Abd al-Qâhir. Kitâb Dalâil Al-I'jâz. Kairo: Maktabah alKhanzi, 2004. 
5. Al-Qurtubi, Abu Abdillah Muhammad Ibn. Tafsîr AlQurtubi/Al-Jâmi' Li Ahkâm alQur" An. Vol. 4. Beirut: Dar alKutub al-Ilmiyyah, 1967.

6. Al-Wâfî, 'Âli Abd al-Wâhid. Fiqh Al-Lugah. Cairo: Dâr al- Nahdah Misr, 1945.

7. - - - Ilm Al-Lugah. Mesir: Martabat Nahdad Mishr bi alFujalah., 1962.

8. Amal, Taufik Adnan. Rekonstruksi Sejarah Al-Quran. Pustaka Alvabet, 2013.

9. Anshori, Muhammad. "Tren-Tren Wacana Studi Al-Qur'an dalam Pandangan Orientalis di Barat" 4, no. 1 (2018): 32.

10. As-Suyûti, Jalaluddin. Al-Itqân Fi Ulûm al-Qu'rân. Bairut: Dar alFikr, 1996.

11. - - - Lubâb An-Nuqûl Fi Asbâb an-Nuzûl. Cairo: Dâr al-Fikr, 2002.

12. Bukhari, Abū 'Abd Allāh Muhammad ibn Ismā'îl ibn Ibrāhīm ibn al-Mughīrah ibn Bardizbah al-Ja'fi Al-Bukhari. 3. Jakarta: Almahira, 2012.

13. Bukhari, Imam al-Ja'fi Al-Bukhari. Vol. 8. Masir: Dar at-Taufiq, 2012.

14. Gorys Keraf, Dr. Diksi Dan Gaya Bahasa. Gramedia Pustaka Utama, 2009.

15. Hafid, Karim. "Relevansi Kaidah Bahasa Arab Dalam Memahami Al-Qur'an," 2016.

16. Halâl, Abd al-Gaffâr Hamîd. 'Ilm al-Lugah Baina al-Qadîm Wa alHadîs. Masir: Dar al-Qalam, 1986.

17. Hasbullah, Moeflich. "5 Indikasi Orang-orang yang 'Menjual Ayat dengan Harga Murah' | UIN SGD Bandung," August 28, 2013. https:// uinsgd.ac.id/5-indikasiorang-orang-yang-menjual-ayatdengan-harga-murah/.

18. Ibn Manzur. "Lisân Al-'Arab," n.d. http://www.lesanarab.com/kalim a/\%D9\%82\%D8\%B1\%D8\%B4.
19. Kambin, Dr Parviz. A History of the Iranian Plateau: Rise and Fall of an Empire. iUniverse, 2011.

20. Latifah, Chori, Muhammad Rohmadi, and Edy Suryanto. "Penggunaan Diksi dalam Karangan Berita Siswa Sekolah Menengah Pertama" 4 (2016): 18.

21. Mahfudz. "Ayat-Ayat Dalam Ekonomi Islam (Versi Lengkap)." Blog Aang (blog), 2019. http:/ / mahfudzirfan.blogspot.com /2019/03/ayat-dalam-ekonomiislam-versi-lengkap.html.

22. Majid, Zamakhsyari Abdul. "Ekonomi dalam Perspektif Alquran." AHKAM: Jurnal Ilmu Syariah 16, no. 2 (December 11, 2016): 251-60. https://doi.org/10.15408/ajis.v16i 2.4455 .

23. Mubaidillah, Mubaidillah. "Memahami Isti' arah Dalam AlQuran." Nur El-Islam 4, no. 2 (2017): 130-141.

24. Qalyubi, Syihabuddin. Stilistika Al-Qur'an: Makna di Balik Kisah Ibrahim. LKIS PELANGI AKSARA, 2008.

25. Qattân, Mannâ Khaîl al-. Mabâhits Fî Ulûm Al-Qur'ân. Riyad: Mansyurât al-'Atr al-Hadîts, 1973.

26. Rahman, Syahrul. "Pro Kontra I'jaz Adady Dalam Al-Qur'an." Jurnal Ushuluddin 25, no. 1 (June 21, 2017): 34. https://doi.org/10.24014/jush.v25 i1.2175.

27. Sanni, Amidu Olalekan. "Hussein Abdul-Raof. Arabic Rhetoric. A Pragmatic Analysis. Reviewed by Amidu Olalekan Sanni." Middle Eastern Literatures 15, no. 1 (April 1, 2012): 97-98. https://doi.org/10.1080/1475262X .2012.657397.

28. Saputri, Amelia, Mulyanto Widodo, and Sumarti Sumarti. “Diksi dalam Poster Berbasis 
Elektronik di Youtube Serta Implikasinya." Jurnal Kata (Bahasa, Sastra, dan Pembelajarannya) 5, no. 1, Apr (2017).

29. Sari, Roza Permata, and Novia Juita. "Analisis Penggunaan (Diksi) Pilihan Kata Oleh Pejabat Legislatif dan Tokoh Partai Tingkat Provinsi Dalam Media Sosial Facebook." Jurnal Bahasa dan Sastra 6, no. 4 (June 25, 2019): 590. https://doi.org/10.24036/8104605 0.

30. Shihab, M. Quraish. Mukjizat AlQuran: Ditinjau Dari Aspek Kebahasaan, Aspek Ilmiah, dan Pemberitaan Gaib. Mizan Pustaka, 1997.

31. - - . "Tafsir Al-Misbah." Jakarta: Lentera Hati, 14, 2 (2002).

32. - - - Wawasan Al-Quran: Tafsir Tematik Atas Pelbagai Persoalan Umat. Mizan Pustaka, 1996.

33. Suaidi, Suaidi. "Dialek-Dialek Bahasa Arab." Adabiyyāt: Jurnal Bahasa dan Sastra 7, no. 1 (July 31, 2008):

79. https://doi.org/10.14421/ajbs.200 8.07105 .

34. Syam, Nurfadhillah, Abd Haris Nasution, and Muhammad Chirzin. "Ma'Anil Quran: Haq, Hayat, Hubb, Hisab Dan Hidayah," August 1, 2018. https://doi.org/10.5281/ZENOD O.1324990.

35. Tanjung, Abdul Rahman Rusli. "Studi Terhadap Kata-Kata yang Semakna dengan Musibah dalam Alquran." Analytica Islamica 2, no. 2 (2013): 262-91.

36. Tarigan, Azhari Akmal. Tafsir Ayat-Ayat Ekonomi Al-Qur'an: Sebuah Eksplorasi Melalui KataKata Kunci. Cita Pustaka Media, 2012.

37. Yuliawati, Susi. "Pilihan Kata dan Konstruksi Perempuan Sunda
Dalam Majalah Manglè Kajian Linguistik Korpus Diakronik." Paradigma, Jurnal Kajian Budaya 7, no. 2 (January 24, 2018): 138. https://doi.org/10.17510/paradig ma.v7i2.172.

38. Zaroni, Akhmad Nur. "Bisnis dalam Perspektif Islam," 2, IV (December 2007): 13. 